\title{
International Risk Sharing and Government Moral Hazard
}

\section{Wolf Wagner}

Published online: 8 May 2007

(C) Springer Science + Business Media, LLC 2007

\begin{abstract}
This paper analyzes incentive problems caused by international risk sharing. They arise because international risk sharing contributes to the insurance of domestic consumption and thus lowers governments' incentives to increase output. We show that the resulting distortions can lead to substantial efficiency losses. Complete risk sharing is, therefore, undesirable and the optimal degree of risk sharing may be low. Furthermore, we show that households' risk sharing decisions are socially inefficient and are effectively maximizing government moral hazard. As a result, financial innovation and integration may reduce welfare by increasing households' risk sharing opportunities.
\end{abstract}

Keywords International risk sharing puzzle • Financial integration • Moral hazard

JEL Classification $\mathrm{D} 52 \cdot \mathrm{F} 30 \cdot \mathrm{F} 36 \cdot \mathrm{F} 40$

\section{Introduction}

Portfolio theory suggests that in order to minimize consumption variability, risks should be completely pooled across countries. Therefore, it is typically taken for granted that facilitating international risk sharing is desirable and that a lack of such risk sharing indicates inefficiencies. The main theme of this paper is that there is also a potential cost to international risk sharing. This is because, by lowering a country's benefits from its output, international risk sharing reduces the country's incentives to produce and thus may cause

\footnotetext{
W. Wagner $(\varangle)$

Department of Economics, TILEC and CentER, Tilburg University,

Postbus 90153, 5000 LE Tilburg, The Netherlands

e-mail: wagner@uvt.nl
} 
inefficient government behavior. Hence, there is a trade-off between risk sharing and incentives, similar to the one that arises in a domestic context.

The aim of this paper is to contribute to the understanding of this tradeoff. This is an important objective, because, first, if international risk sharing causes distortions in production, complete risk sharing may be sub-optimal. Such a result may help to understand the small degree of risk sharing across countries, which has been pointed out by several authors. For example, only around 5\% of income shocks in OECD countries are insured (Sørensen and Yosha 1998) compared to the $100 \%$ income insurance that portfolio theory would suggest. Up to now, no widely accepted resolution for this international risk sharing puzzle exists. ${ }^{1}$

Second, the analysis may inform about whether households' risk sharing choices are socially optimal and whether there is a case for government intervention. Earlier work has found that in a closed economy markets solve the risk sharing-incentive trade-off in an efficient way (Kocherlakota 1998; Calcagno and Wagner 2006), but this result may not extend to an international setting.

We show that when households can trade assets that condition on output, equilibrium risk sharing is characterized by output diversification in perpetuity. Under such risk sharing, domestic households hold claims to world output in all future periods and have sold claims to the output of their own country. This form of risk sharing is particularly problematic for government incentives. First, it does not allow for the costs of production to be shared among countries. Since at the same time a country's benefits from production are reduced to the extent that it is diversified, governments have an incentive to lower inputs into production. This may be either directly (for example, through reduced public investment) or indirectly, by discouraging households from supplying inputs (for example by taxing labor). Second, because households' optimal risk sharing involves diversification of perpetual claims to output (otherwise they would not be insured against permanent shocks), a country does not suffer any future costs from inefficient policies, which would normally help to mitigate moral hazard issues. For example, if government policies cause an outflow of capital that results in lower domestic income in future periods, the country would not internalize this as claims to its income are held by households from other countries.

We also show that equilibrium risk sharing is inefficient from a social perspective. The reason for this is that an individual household ignores the impact of its risk sharing decision on government policies. ${ }^{2}$ Therefore, it does not obtain risk sharing that is less detrimental to incentives, even if this would be possible. Suppose, for example, that besides assets conditioning on

\footnotetext{
${ }^{1}$ For an overview over the substantial literature on this puzzle, see Lewis (1999).

${ }^{2}$ This is due to a 'common-agency' problem (as analyzed in the international context by Tirole 2002, 2003): the government acts as a common agent for domestic households. By influencing the behavior of the common agent, a single household poses externalities for the other households in the economy.
} 
output, all domestic production inputs could also be traded. Complete risk sharing could then be obtained without creating any incentive problems by diversifying a country's net income (that is, output net of costs), as the costs of providing inputs would then be shared with foreigners. However, an individual household has no incentive to obtain such complex risk sharing, as output diversification already achieves complete risk sharing.

To illustrate the magnitude of the incentive problems, we show that the potential costs of government moral hazard can be large. In particular, they can easily outweigh the gains from risk sharing and can cause the optimal degree of risk sharing to be low. Therefore, the low degree of risk sharing in the data does not necessarily indicate an inefficient level of risk sharing.

Another implication of our analysis is that financial integration and financial innovation that allow for better risk sharing may reduce welfare. This is because they may facilitate risk sharing beyond the socially optimal level. ${ }^{3}$ Recently, so-called Economic Derivatives have been introduced (see, for example, The Economist 2002). These instruments allow individuals to hedge country risks, for example, by trading a country's GDP. While this innovation surely brings about considerable gains by improving diversification, our results indicate that it may also imply significant costs.

The concern that international risk sharing may entail costs by causing inefficient government policies is not a new one (see Shiller 1993; Wincoop 1999; Drèze 2000). However, there has not been a formal analysis of such costs yet. This paper contributes in particular by studying how they tradeoff with the benefits from international risk sharing and by considering the consequences for the optimal degree of risk sharing.

Several papers have analyzed the implications of moral hazard for the pattern of risk sharing and capital flows across countries. In Gertler and Rogoff (1990), moral hazard on the side of the government can explain why capital may flow from poorer to richer countries, even though rates of return in the latter are lower. Atkeson (1991) has shown that capital outflows in a crisis can be an efficient outcome (even though suboptimal in terms of risk sharing), when risk sharing is impeded by moral hazard and a lack of contract enforcement. Tirole (2003) uses government moral hazard to explain the structure of external financing in developing countries. These papers study the pattern of risk sharing that a benevolent social planner would implement. By contrast, the point of departure in the present paper is risk sharing that is initiated by households. We analyze how such risk sharing interacts with government incentives and show that it has very different welfare implications.

While this paper is concerned with distortions in production in general, several previous contributions have suggested specific channels through which inefficiencies can arise, mostly in the context of cross-ownership of assets

\footnotetext{
${ }^{3}$ It has been argued that financial integration also disciplines governments by making capital more sensitive to macroeconomic policies (e.g., Fischer 1998). Our analysis suggests that such a disciplining effect may be mitigated because financial integration also facilitates risk sharing and thus insulates a country from the consequences of capital outflows following bad policies.
} 
rather than explicitly risk sharing. Examples are distortions in corporate governance and bankruptcy laws (Tirole 2003), in crisis prevention (Tirole 2002, 2003), in labor protection (Atkeson 1991), in the taxation of firms (Huizinga and Nielsen 1997), in public inputs (Sachs 1989), in the incentives to undertake economic reforms (Calvo 2000), and in debt service (Kremer and Mehta 2000).

The remainder of this paper is organized as follows. In the next section, we demonstrate the moral hazard problem that arises from international risk sharing. Section 3 examines the equilibrium of household risk sharing and government policies. In Section 4 we discuss some mechanisms that may in practice help to mitigate government moral hazard. Section 5 studies the optimal degree of output diversification and analyzes the connection to the observed lack of international risk sharing. The final section contains the conclusions.

\section{International risk sharing and domestic production}

The world consists of a continuum of ex-ante identical countries, indexed with $i$. Each country is inhabited by a continuum of households, indexed with $j$. There is only one period. Households maximize expected utility $E\left[u\left(c_{j}^{i}\right)\right]$, where $c_{j}^{i}$ denotes consumption. Production by household $j$ in country $i$ is given by

$$
y_{j}^{i}=f\left(x_{j}^{i}\right) \eta^{i}
$$

where $\eta^{i}$ is a country-specific shock giving rise to a risk sharing motive (we abstract here from household specific uncertainty; one may imagine that such uncertainty is already completely shared within a country). $x_{j}^{i}$ is an arbitrary input to production, which is either chosen by households or the government. The interpretation of $x_{j}^{i}$ is broad. Besides private inputs (e.g., capital and labor) and public inputs (e.g., infrastructure) it may, for example, also stand for efforts to undertake economic reforms that raise output. The supply of these inputs causes costs $z\left(x_{j}^{i}\right)$, which are expressed in terms of output (e.g., if $x$ refers to capital in the form of the output good, then $z(x)=x$ ). Furthermore, we assume standard regularity conditions that ensure interior solutions to the input choice: $f^{\prime}(x)>0, f^{\prime \prime}(x)<0, \lim _{x \downarrow 0} f^{\prime}(x)=\infty$ and $z^{\prime}(x)>0, z^{\prime \prime}(x) \geq$ $0, \lim _{x \downarrow 0} z^{\prime}(x)=0$.

We assume, moreover, that international risk sharing is characterized by output diversification (in the next section we endogenize the risk sharing decision and show that such output diversification is indeed the preferred choice of households). Analogous to portfolio diversification, output diversification can be achieved through selling claims to domestic output and buying claims to world output (the equivalent of the world market portfolio). Denote with $b(0 \leq b \leq 1)$ the share of domestic production diversified. Households' consumption is then given by

$$
c_{j}^{i}=y\left(x_{j}^{i}\right)-z\left(x_{j}^{i}\right)+b\left(y^{*}-y\right)
$$


where $y$ and $y^{*}$ denote domestic and world output (expressed in per capita terms), respectively. Obviously, for a given $x_{j}^{i}$ an increase in $b$ is welfare increasing because it reduces consumption risk. For $b=1$, one obtains the standard full risk sharing allocation: $c_{j}^{i}=y^{*}-z^{*}$, implying that consumption is ex-post equalized across countries (follows from Eq. 2, after imposing symmetry: $x_{j}^{i}=x$ and $z^{i}=z$ ).

Consider first the optimal choice of inputs by households. From Eq. 2, the first order condition for $x_{t}^{i}$ is

$$
E\left[u^{\prime}\left(c_{j}^{i}\right) y^{\prime}\left(x_{j}^{i}\right)\right]=E\left[u^{\prime}\left(c_{j}^{i}\right) z^{\prime}\left(x_{j}^{i}\right)\right]
$$

which would imply an efficient choice of $x_{t}^{i}$ and hence there would be no distortions in production. Consider next the choice of inputs by the government of country $i$. From integrating Eq. 2 over $j$ and applying symmetry we have the budget equation of country $i$

$$
c^{i}=(1-b) y\left(x^{i}\right)+b y^{*}-z\left(x^{i}\right)
$$

Hence, for a government that maximizes domestic welfare, the first order condition for $x^{i}$ is

$$
(1-b) E\left[u^{\prime}\left(c^{i}\right) y^{\prime}\left(x^{i}\right)\right]=E\left[u^{\prime}\left(c^{i}\right) z^{\prime}\left(x^{i}\right)\right]
$$

Thus, in contrast to households, the government perceives lower benefits of $x^{i}$ and hence chooses an $x^{i}$ lower than the efficient level. This is because it takes into account that for the country as a whole, a share $b$ of domestic output is insured, while the cost of supplying inputs is still fully borne by the residents.

Alternatively, Eq. 5 is also obtained if households choose $x_{j}^{i}$ but governments can influence households' incentives to supply inputs. To see this, suppose for example that the government can levy a tax $t^{i}$ on production. Analogous to Eqs. 2 and 3, the household's budget equation and first order condition can be expressed as

$$
\begin{aligned}
c_{j}^{i} & =\left(1-t^{i}\right) y\left(x_{j}^{i}\right)-z\left(x_{j}^{i}\right)+b\left(y^{*}-y^{i}\right) \\
\left(1-t^{i}\right) E\left[u^{\prime}(c) y^{\prime}\left(x^{i}\right)\right] & =E\left[u^{\prime}(c) y^{\prime}\left(z^{i}\right)\right]
\end{aligned}
$$

By setting $t^{i}=b$, the government can then implement its first order condition (5). Summarizing, we can hence conclude that

Result 1 Output diversification leads to distortions in all production inputs that can, directly or indirectly, be controlled by the government.

Anecdotal evidence supports the existence of distorting government policies due to risk sharing (or, similarly, due to cross-ownership of assets). For example, it has been argued that Canadian provinces have raised their labor taxes because a federal unemployment insurance system allowed them to shift part of the costs of tax increases (arising from higher unemployment) to the federal government (Courchene and Purvis 1993). In our setup, unemployment insurance would correspond to insurance (or 'foreign ownership') of the labor income of a provence. As labor income constitutes a part of total income, 
incentives to raise the latter are reduced. Consequently, it may be optimal for the government to raises taxes on inputs (however, as only the labor income part is insured, it is more efficient to levy taxes directly on labor in order to avoid distortions in other inputs).

Furthermore, in the aftermath of the Asian crises, commentators have held foreign ownership of debt and equity responsible for delays in reforms in the affected countries. Debt and equity can be understood as a claims to domestic capital income and thus their foreign ownership leads to partial insurance of capital income. Hence, incentives to provide effort in raising output (of which capital income is a part) through a reform are reduced.

There is also econometric evidence consistent with government policies causing production distortions due to foreign ownership of assets: Eijffinger and Wagner (2001) provide panel evidence from US states that higher foreign ownership of firms leads to higher capital taxes. Huizinga and Nicodème (2006) find similar evidence for capital taxes on the firm level for the EU. ${ }^{4}$

\section{Risk sharing and production in equilibrium}

In this section, we endogenize households' risk sharing choices. Households can now freely trade securities internationally and also fully anticipate possible distortions in the inputs by governments. Furthermore, we extend to an infinite horizon setting, where risk sharing, the choice of inputs and consumption take place in every period. The government's choice of inputs in a period can then have consequences for households' consumption in future periods. This would allow, in principal, for the mitigation of government moral hazard through reputation mechanisms or the threat of capital flight.

To focus on the core issues, we refrain from modelling household production explicitly. Rather, we directly assume that households have a claim to aggregate output net of its cost and that the production input is set by the government (since private inputs are set efficiently regardless of risk sharing (Eq. 3) we suppress them in the analysis).

Aggregate output and costs in per capita terms are now given by $y_{t}^{i}=f\left(x_{t}^{i}\right) \eta_{t}^{i}$ and $z\left(x_{t}^{i}\right)$, respectively. $t(t=0,1,2, \ldots)$ denotes time. The single input $x_{t}^{i}$ is exclusively chosen by the government. A household's endowment is given by $f\left(x_{t}^{i}\right) \eta_{t}^{i}-z\left(x_{t}^{i}\right)$. The $\eta_{t}^{i}$ are drawn independently across countries from the per-period density-function $\phi_{t}\left(\eta_{t}^{i}\right)$, which has full support on $(0, \infty)$. This specification ensures two properties. First, from independence across countries and the assumption of full support in every period, it follows that two shocks are never fully correlated, neither across countries nor across time. Second, from full support we have that for each $f\left(x_{j}^{i}\right)>0$ each realization of output $y_{t}^{i}$

\footnotetext{
${ }^{4}$ An example that vividly demonstrates that governments are taking non-residents into consideration when setting their policies comes from US state taxation: all US states tax hotel and motel occupancy (which are disproportionally used by out-of-state residents) at a higher rate than the general sales tax (Pollock 1991).
} 
on $(0, \infty)$ is possible. Hence, one cannot deduce the input $x_{t}^{i}$ from observing $y_{t}^{i}$ (which would do away with the moral hazard problem).

At $t=0$, households can trade the complete set of securities that are contingent on output. More specifically, for each period $t$ and for each realization of past outputs $\left\{y_{\leq t}\right\}$ (that is a realization of all countries' outputs up to period $t$ ), there is a security that pays off one unit of output in $t$ when the output realization was $\left\{y_{\leq t}\right\}$ and zero otherwise. We denote the quantity of output security $\left\{y_{\leq t}\right\}$ held by a household at time $t$ by $q_{j, t}^{i}\left(\left\{y_{\leq t}\right\}\right)$ and its price by $p_{t}\left(\left\{y_{\leq t}\right\}\right)$.

Note that the restriction to output contracts is important. If either shocks, inputs or costs were contractible, it is easy to see that the first best could be in principal attained as full risk sharing would then be possible without distorting production incentives. The motivation for restricting us to output contracts is that country shocks, production inputs and the costs of providing inputs are too complex to write contracts on (they may even not be observable). Such contracts are also not commonly observed in practice. On the other hand, output contracts can be based on a single observable variable and are already traded (see Remark 1 below). Moreover, we argue later (Remark 6) that even if such contracts are available, they are not used in equilibrium.

Households' maximization problem at $t=0$ is given by

$$
\begin{gathered}
\max _{\left\{q_{j, t}^{i}\left(\left\{y_{\leq t}\right\}\right)\right\}} E_{0}\left[\sum_{t=0}^{\infty} \delta^{t} u\left(c_{j, t}^{i}\right)\right], \text { subject to } \\
c_{j, t}^{i}\left(x_{t}^{i}, \eta_{t}^{i},\left\{y_{\leq t}\right\}\right)=f\left(x_{t}^{i}\right) \eta_{t}^{i}-z\left(x_{t}^{i}\right)+q_{j, t}^{i}\left(\left\{y_{\leq t}\right\}\right) \text { with } t=0,1,2, \ldots \\
\sum_{t=0}^{\infty} \int_{\left\{y_{\leq t}\right\}} p_{t}\left(\left\{y_{\leq t}\right\}\right) q_{j, t}^{i}\left(\left\{y_{\leq t}\right\}\right)=0
\end{gathered}
$$

where Eq. 9 is a household's consumption equation for each period $t$ and Eq. 10 its budget restriction for trade at $t=0$.

At each $t$, governments (independently) choose inputs in order to maximize the sum of the expected utility of their countries' residents, i.e. country $i^{\prime} s$ government maximizes

$$
\max _{x_{t}^{i}} \int_{j} E_{t}\left[\sum_{s=t}^{\infty} \delta^{t} u\left(c_{j, s}^{i}\right)\right]
$$

Zero-net supply of output securities requires

$$
\int_{i, j} q_{j, t}^{i}\left(\left\{y_{\leq t}\right\}\right)=0
$$

The timing can be summarized as follows. At $t=0$, households trade securities, i.e., choose the $q_{j, t}^{i}$ 's. Afterwards, at each $t$ governments choose inputs $x_{t}^{i}$, the shocks $\eta_{t}^{i}$ realize and households consume $c_{j, t}^{i}$. 


\section{Proposition 1 In equilibrium,}

(1) Households obtain complete risk sharing: $u^{\prime}\left(c_{j, t}^{i}\right)$ is constant across individuals,

(2) Households' consumption is independent of their country's output: $\partial c_{j, s}^{i} / \partial y_{t}^{i}=0$,

(3) Governments set inputs ignoring the impact on domestic output: $x_{t}^{i}$ fulfills $z^{\prime}\left(x_{t}^{i}\right)=0$.

Proof

(1) In equilibrium, households rationally anticipate government policies $\{x\}$. Furthermore, since households are atomistic they take $\{x\}$ as given. Hence, they also take as given the probability density for output, denoted $\psi_{t}\left(y_{t}^{i}\right)$ with $\psi_{t}\left(y_{t}^{i}\right):=f\left(x_{t}^{i}\right) \cdot \phi_{t}\left(\eta_{t}^{i}\right)$. The household's first order condition for an output security that pays off when $\left\{y_{\leq t}\right\}$ has occurred can then be expressed as

$$
\psi_{t}\left(y_{t}^{i}\right) \delta^{t} u^{\prime}\left(c_{j, t}^{i}\left(\left\{y_{\leq t}\right\}\right)\right)-\lambda_{j}^{i} \pi\left(\left\{y_{\leq t}\right\}\right)=0
$$

where $\lambda_{j}^{i}$ is the Lagrange-multiplier associated with budget equation (10). Since households are identical at $t=0 \Rightarrow \lambda_{j}^{i}=\lambda \Rightarrow u^{\prime}\left(c_{j, t}^{i}\right)=$ $\delta^{-t} \lambda \pi_{t}\left(\left\{y_{\leq t}\right\} / \psi_{t}\left(y_{t}^{i}\right) \Rightarrow u^{\prime}\left(c_{j, t}^{i}\right)\right.$ (and thus $\left.c_{j, t}^{i}\right)$ is constant across households.

(2) From (1) it follows that $c_{j, t}^{i}=c_{t}^{*}$, where $c_{t}^{*}$ is (per capita) world consumption. Since $\operatorname{var}\left(c_{t}^{*}\right)=0$ (follows by the law of large numbers from the independence of $\eta_{t}^{i}$ across countries $) \Rightarrow \operatorname{var}\left(c_{j, t}^{i}\right)=0$. Since $\operatorname{var}\left(\eta_{t}^{i}\right)>0$ and shocks are by assumption not fully correlated (neither across countries nor across time), it follows from Eq. 9 that $q_{j, t}^{i}\left(\left\{y_{\leq t}\right\}\right)=$ $q_{j, t}^{i}\left(y_{t}^{i}\right)=-y_{t}^{i}+C_{j, t}^{i}$, where $C_{j, t}^{i}$ is some constant. Thus, $\partial c_{j, t}^{i} / \partial y_{t^{\prime}}^{i \prime}=0$ for arbitrary $i, i^{\prime}, j, t, t^{\prime}$ (note that this is not true if there are shocks that are perfectly correlated: $\operatorname{var}\left(c_{j, t}^{i}\right)=0$ can then be obtained through securities paying off contingent on output other than $y_{t}^{i}$, e.g., with $q_{j, t}^{i}=-y_{t-1}^{i}+C$ if $\left.\operatorname{cor}\left(y_{t-1}^{i}, y_{t}^{i}\right)=1\right)$.

(3) The government's first order condition at $t$ is

$$
\int_{j} \frac{d E_{t} \sum_{s=t}^{\infty} \delta^{s} u\left(c_{s}^{i}\right)}{d x_{t}^{i}} d j=\frac{d E_{t} \sum_{s==}^{\infty} \delta^{s} u\left(c_{s}^{i}\right)}{d x_{t}^{i}}=0
$$

where the second term follows from suppressing index $j$ because of symmetry. With Eq. 9 this can be written as

$$
E_{t}\left[\sum_{s=t}^{\infty} \delta^{s} u^{\prime}\left(c_{s}^{i}\right)\left(\frac{\partial c_{s}^{i}}{\partial y_{t}^{i}} \frac{\partial y_{t}^{i}}{\partial x_{t}^{i}}\right)\right]-\delta^{t} u^{\prime}\left(c_{s}^{i}\right) z^{\prime}\left(x_{t}^{i}\right)+E_{t}\left[\sum_{s=t+1}^{\infty} \delta^{s} \frac{d u\left(c_{s}^{i}\right)}{d x_{t+1}^{i}} \frac{d x_{t+1}^{i}}{d x_{t}^{i}}\right]=0
$$

Since $\partial c_{s}^{i} / \partial y_{t}^{i}=0$ (from (2)), $E_{t+1}\left[\sum_{s=t+1}^{\infty} \delta^{s}\left(d u\left(c_{s}^{i}\right) / d x_{t+1}^{i}\right)\right]=0$ (envelope theorem for $x_{s}^{i}, s \geq t+1$ ) and $E_{t}\left[E_{t+1}[\cdot]\right]=E_{t}[\cdot]$ (law of iterated expectations), Eq. 15 simplifies to $z^{\prime}\left(x_{t}^{i}\right)=0$. 
The intuition behind Proposition 1 is as follows. (1): A single household behaves atomistically and takes domestic output, domestic cost, and security prices as given. Therefore, its objective is reduced to minimizing consumption variability. Hence, it chooses full risk sharing (2): Since shocks are not fully correlated (and no contracts can be written on shocks), the only way for households to hedge completely against domestic shocks (in order to obtain full risk sharing) is to sell output securities that fully offset their claim to domestic output. (3): As a consequence of (2), domestic output for all future periods is effectively sold at $t=0$. A government can then not influence domestic gross income (i.e., domestic output plus payments from the securities) anymore. However, domestic consumption still fully depends on domestic costs (which are, by assumption, not tradeable), hence the government chooses the inputs in order to minimize these costs.

Another way to understand the independence of domestic gross income from government actions is the following. Suppose, to the contrary, that a government could affect a household's income, say $\partial v_{s}^{k} / \partial x_{t}^{i} \neq 0$ (where $v_{s}^{k}:=y_{s}^{k}+q_{s}^{k}$ is a household's gross income) for some $i, k$ and $s, t$. Then, $v_{s}^{k}$ would depend on $y_{t}^{i}$ (from Eq. 9 we have $d v_{k}^{s} / d x_{t}^{i} \neq 0 \Rightarrow \partial v_{k}^{s} / \partial y_{t}^{i} \neq 0$ ). But this implies that $v_{s}^{k}$ also depends on $\eta_{t}^{i}$ (from Eq. 9: $\partial v_{k}^{s} / \partial y_{t}^{i} \neq 0 \Rightarrow \partial v_{k}^{s} / \partial \eta_{t}^{i} \neq 0$ ), contradicting full risk sharing.

Remark 1 (Equilibrium asset positions) From the proof of (2) we have $q_{j, t}^{i}\left(\left\{y_{\leq t}\right\}\right)=-y_{t}^{i}+C_{j, t}^{i}$. Integrating over $i$ and $j$ and using $C_{j, t}^{i}=C_{t}$ (since countries are ex-ante identical) and Eq. 12 gives $C_{t}=y_{t}^{*}$, where $y_{t}^{*}$ is world production in per capita terms. Hence, $q_{j, t}^{i}\left(\left\{y_{\leq t}\right\}\right)=y_{t}^{*}-y_{t}^{i}$. Therefore, households' asset positions are simple diversification securities: households sell claims to domestic output and buy claims to world output. Such contracts are feasible since the recent introduction of Economic Derivatives which, among others, allow to trade forwards on GDP (see The Economist, October 19th, 2002).

Remark 2 (One-period securities) Trading output securities in each period that pay off in the next period (instead of trading the complete set at $t=0$ ) does not change the equilibrium outcome. The reason is that households can use these securities to replicate the complete set of securities (see, e.g., Magill and Quinzii 1998).

Remark 3 (Timing) The results are not sensitive to the assumption that at $t=0$ asset trade takes place before the government sets the input for the period. To see this, suppose to the contrary that the government moves first in $t=0$. Then, inputs would be set efficiently in this period, as domestic households would suffer from any inefficiencies through a lower price they can obtain when they sell domestic output (recall from Remark 1 that households trade domestic output for world output). However, from $t=1$ on, the moral hazard problem is as before. This is because the potential presence of permanent shocks requires households to insure output in perpetuity. Therefore, from 
$t=1$ on, the government finds the output in each current period already insured (things would change, obviously, if the government could at $t=0$ commit also to inputs for future periods; this possibility is discussed in the next section).

Remark 4 (Costs of moral hazard that materialize in future periods) Government moral hazard may be mitigated because an inefficient choice of inputs in the current period may have negative implications for future periods. For example, inefficient production in period $t$ may trigger a capital flight in period $t+1$, and reduce future income for the country. Although our setup allows for such mechanisms because there is an infinite horizon, they are not operative in equilibrium (such mechanisms are discussed in more detail in the next section). This is because full risk sharing requires output to be insured in perpetuity (and not just in the current period). A country, therefore, does not suffer from a lowering of its income in future periods.

Remark 5 (Inefficiency of equilibrium risk sharing) Because households choose risk sharing without considering its social costs (which arise from distortions in aggregate production), the equilibrium allocation is (constrained)inefficient. This result is diametrical to previous work (e.g. Kocherlakota 1998; Magill and Quinzii 2002). In these contributions markets for individual production (as opposed to aggregate production) have been studied and were found to operate efficiently in the presence of incentive problems. The reason for this is that when a household sells claims to its own production, its incentives to produce are reduced. This is anticipated by the buyer and internalized through a lower price the household obtains for selling its own production. By contrast, in the present setting, a household fails to internalize inefficiencies since they arise for aggregate production and are thus equally borne by all households.

Remark 6 (Other securities) The assumption that only output securities are tradeable can be relaxed without changing the equilibrium outcome. This is because output securities suffice to achieve full risk sharing. As households ignore the impact of their risk sharing decision on aggregate incentives and only strive for maximal risk sharing, there do not exist other securities that are (individually) strictly preferred by households over output securities. In particular, if other securities beside output securities can be traded (for example, securities conditioning on inputs) but such securities do not allow for full risk sharing (for example, because not all inputs are contractible or because inputs can only be measured imprecisely), they are not used by households (even though this may be socially desirable). The same holds if such securities occur higher costs than output securities (for example, because of costly state verification or transaction costs), which is likely to be the case as output securities only require conditioning on a single observable variable.

Remark 7 (Costly risk sharing) The extreme nature of Proposition 1 is a consequence of the assumption that achieving full risk sharing is costless for 
households. Suppose to the contrary that there are some costs in obtaining risk sharing (e.g., transaction costs). Still, households would only trade securities $q_{j, t}^{i}\left(y_{t}^{i}\right)=y_{t}^{*}-y_{t}^{i}$ (from Remark 1) because they are the most effective for obtaining risk sharing. However, since risk sharing is now costly, households may only obtain partial insurance. Rather than having $\partial c_{t}^{i} / \partial y_{t}^{i}=0$ (which would be implied by full insurance) we may have, say, $\partial c_{t}^{i} / \partial y_{t}^{i}=\left(1-b_{t}^{i}\right) \geq 0$. Note that this $b_{t}^{i}$ corresponds to the diversification degree defined in Eq. 4. Since the government's optimization problem is a static one (as households trade securities $q_{j, t}^{i}\left(y_{t}^{i}\right)$ that only depend on current but not past output), its first order condition can be expressed as (dropping the time subscript)

$$
E\left[\delta^{t} u^{\prime}\left(c^{i}\right)(1-b)\right]-E\left[\delta^{t} u^{\prime}\left(c^{i}\right) z^{\prime}\left(x^{i}\right)\right]=0
$$

which follows from Eq. 15 using $\partial c_{t}^{i} / \partial y_{t}^{i}=(1-b)$. Equation 16 is identical to Eq. 5. Hence, the government's first order condition in Section 2 can be understood as applying to the per-period choice of inputs in a world with multiple periods and costly risk sharing.

\section{Factors limiting inefficiencies in government policies}

Proposition 1 predicts that if households can trade securities that allow for effective risk sharing across countries, they will insure domestic production and motivate governments to choose inefficient policies. In practice, there are several mechanisms that may mitigate this government moral hazard. In this section, we review some of them and argue that they are unlikely to overcome inefficiencies in government policies.

Commitment Obviously, if governments can commit, the first best is attainable simply by committing to the efficient level of $x$ (as defined by Eq. 3). However, governments have only an incentive to do so before risk sharing takes place (otherwise, the previous section's setup readily applies). An effective commitment seems also unfeasible because production inputs are not always measurable or observable (think for example of human capital). It is also unrealistic in that the government would need to commit to all policies that affect inputs into the infinite future in order to achieve the first best. ${ }^{5}$

Reputational considerations Governments may be reluctant to lower inputs because this may damage their reputation with foreigners. In Remark 5 we have discussed that there is no reputation mechanism in our model, since a country is fully insured against the negative repercussions that may arise in terms of lower future income. Besides, there may also be reputational spillovers to other external relationships the government has and which are not necessarily captured by our setup (such spillovers have been emphasized in the sovereign risk literature, e.g., Eaton and Gersovitz 1981). However, the case

\footnotetext{
${ }^{5}$ Another problem is that such commitment may also not be desirable because it implies a loss of flexibility for countries in responding to shocks.
} 
for such spillovers is not strong. This is because inefficient policies are fully anticipated and, therefore, priced into the securities. Hence, in equilibrium foreign investors do not suffer from inefficient government policies.

International mobility of capital Inefficient inputs are likely to reduce the return on capital. As a result, there may be a capital outflow, with potentially negative repercussions for the country. For example, the capital outflow may lead to a reduction in tax revenues or the return on labor. It has been commonly asserted that this can exert a disciplining effect on governments (e.g., Fischer 1998). As already discussed, due to households' desire to isolate themselves from fluctuations in their country's income, a country will be insured against such effects when effective means for international risk sharing are available. Risk sharing may thus remove the discipline provided by internationally mobile capital.

However, this only holds when risk sharing allows to insure all parts of domestic income. If this is not the case (for example, because only capital income can be insured), a country may suffer from a lower capital stock through its impact on the uninsured parts of national income (e.g., lower tax revenues and labor income). Therefore, our analysis cannot be readily applied to the home bias in portfolio investment (French and Poterba 1991) if portfolio diversification is the main way through which international risk sharing takes place. ${ }^{6}$

Inability of the government to influence inputs There are certainly restrictions in the government's ability to influence production inputs, may it be due to administrative, legal or political constraints. When this leads to inputs being chosen by households, their provision will be efficient (as shown in Section 2). However, in developed countries with a functioning political system and a functioning executive, governments have wide-ranging possibilities to influence production inputs. For example, they can set tax rates, which in turn determine household's incentives to supply inputs. Or, governments can introduce laws that govern the supply of inputs, for example through labor laws that determine the number of weekly working hours. Governments also set inputs in the public sector, which constitutes a large part of the economy in developed countries. Thus, governments can probably control a large share of overall inputs.

\section{Optimal diversification}

In this section we analyze the socially optimal degree of output diversification, i.e., the degree of diversification that maximizes households' welfare when incentive problems are present in the economy.

\footnotetext{
${ }^{6}$ To the contrary, evidence suggests that international risk sharing takes place through a variety of channels rather than portfolio diversification alone (e.g., Sørensen and Yosha 1998). Also, it has been argued that the scope for additional risk sharing lies mainly in the sharing of labor income risk (e.g., Shiller 1993).
} 
This degree does not necessarily coincide with socially optimal risk sharing, i.e., there may be contracts that can improve upon the trade-off between risk sharing and incentives. However, output diversification is households' preferred choice of risk sharing (as shown in Section 4) and therefore provides a natural benchmark in a world where risk sharing is mainly achieved by households. It is in particular useful to understand the welfare implications of financial innovation and integration through their impact on household risk sharing. Output diversification also translates directly into a degree of income insurance, which is the common way of measuring the extent of risk sharing in the data (see, for example, Sørensen and Yosha 1998).

We focus in this section on a single period. This is appropriate since, as we have argued earlier (Remark 7), the optimization problem under output diversification is essentially a static one. We interpret $x$ now as the aggregate (or representative) input of the country, i.e., $x$ refers to the combination of all production inputs.

We assume that the supply of $x$ in the economy is characterized by the following equation

$$
\left.(1-\chi b) E\left[u^{\prime}(c) y^{\prime}(x)\right]=E\left[u^{\prime}(c) z^{\prime}(x)\right)\right]
$$

where we have suppressed the country indices. In Eq. 17, $\chi(0 \leq \chi \leq 1)$ is a reduced form parameter that stands for the importance of factors that limit moral hazard. In fact, from Eqs. 3 and 5 in Section 2 it can be appreciated that Eq. 17 is a linear combination of the condition for the efficient choice of $x$ and the condition for the government's choice of $x$ (Eq. 5), with $\chi$ being the relative weight on the latter.

We interpret Eq. 17 as the reduced form condition for the supply of $x$ in an economy where mitigating forces to government moral hazard (as described in the previous section) are present. The motivation is the following. If mitigating forces are absent, $x$ is chosen according to Eq. 5, corresponding to $\chi=1$ in Eq. 17. If the forces are partly effective, $x$ will be chosen more efficiently, which can be represented in Eq. 17 by a $\chi$ lower than one. In the case of fully effective forces, $x$ is chosen according to Eq. 3, corresponding to $\chi=0$. Hence, varying degrees of effectiveness of the mitigating forces (in terms of reducing government moral hazard) can be represented in Eq. 17 by varying $\chi$ between zero and one.

The country-shock $\eta$ is now assumed to have two components: an idiosyncratic shock $\varepsilon$ and an aggregate (world) shock $\varepsilon^{*}$. Both shocks have zero mean and variances $\sigma^{2}$ and $\sigma^{* 2}$, respectively, and are assumed to be uncorrelated with each other. The idiosyncratic shocks $\varepsilon$ are also uncorrelated across countries. Hence, we can write $\eta=1+\varepsilon+\varepsilon^{*}$ and $\operatorname{var}(\eta)=\sigma^{2}+\sigma^{* 2}$. Domestic output and world output are then given by $y(x)=f(x)\left(1+\varepsilon+\varepsilon^{*}\right)$ and $y^{*}=$ $f^{*}\left(1+\varepsilon^{*}\right)$, respectively (the latter follows because the country-specific shocks cancel out due to the law of large numbers).

For the coming analysis, it is useful to express consumption $c$ in terms of its certainty equivalent, denoted $\widetilde{c}$. The latter is defined implicitly by $E[u(c)]=$ 
$u(\widetilde{c})$. Denoting with $\bar{c}=E[c]$ expected consumption, $\widetilde{c}$ is approximately equal to $\bar{c}-u^{\prime \prime}(\bar{c}) / u^{\prime}(\bar{c}) \cdot \operatorname{var}(c) / 2$ for when the variance of consumption is small (Pratt 1964). From Eq. 2 we get for $\widetilde{c}$

$$
\widetilde{c} \approx\left(1-\frac{u^{\prime \prime}(\bar{c}) f(k)}{u^{\prime}(\bar{c})} \frac{(1-b)^{2} \sigma^{2}+\sigma^{* 2}}{2}\right) f(k)-z(k)
$$

where we have made use of symmetry across countries, i.e., $f(k)=f^{*}$. Assuming constant relative risk aversion and approximating the relative risk aversion parameter $\gamma$ by $-u^{\prime \prime}(\bar{c}) f(k) / u^{\prime}(\bar{c})$ yields

$$
\begin{aligned}
\widetilde{c} & \approx\left(1-\frac{\gamma}{2}\left[(1-b)^{2} \sigma^{2}+\sigma^{* 2}\right] f(k)-z(k)\right. \\
& =(1-\pi) f(k)-z(k)
\end{aligned}
$$

where

$$
\pi=\frac{\gamma}{2}\left[(1-b)^{2} \sigma^{2}+\sigma^{* 2}\right]
$$

is the risk premium for production. Using Eq. 20, Eq. 17 can be written as

$$
(1-\chi b)(1-\pi) f^{\prime}(x)=z^{\prime}(x)
$$

The optimal degree of risk sharing $b^{*}$ is then the $b$ that maximizes $\widetilde{c}$ subject to Eq. 22. To understand its determinants, we consider the marginal welfare effect of an increase in risk sharing (i.e., an increase in $b$ by $d b$ )

$$
\widetilde{c}(b)=-\pi^{\prime}(b) f(x)+\left[(1-\pi) f^{\prime}(x)-z^{\prime}(x)\right] x^{\prime}(b)
$$

$z^{\prime}(x)$ can be substituted using Eq. 22 to yield

$$
\begin{aligned}
\widetilde{c}(b) & =-\pi^{\prime}(b) f(x)+\chi b(1-\pi) f^{\prime}(x) x^{\prime}(b) \\
& =\left[-\pi^{\prime}(b)+\chi b(1-\pi) \phi_{f, b}\right] f(x)
\end{aligned}
$$

where $\phi_{f, b}=f^{\prime}(x) x^{\prime}(b) / f(x)$ is the semi-elasticity of production with respect to the extent of risk sharing $b$.

The first term in Eq. 24, $-\pi^{\prime}(b)>0\left(-\pi^{\prime}(b)>0\right.$ follows from Eq. 21), represents the direct benefits from risk sharing due to a lower risk premium. The second term, $\chi b(1-\pi) \phi_{f, b}$, arises from the impact of diversification on production. Since $1-\pi>0$ (follows from Eq. 22), $\chi b(1-\pi)$ is positive for $\chi>0, b>0$. Hence, additional production is welfare increasing (intuitively, this is because there is underprovision of inputs for when $\chi>0, b>0$ ). The welfare effect of the second term depends, therefore, on the sign of $\phi_{f, b}$, and thus on $x^{\prime}(b)$ as determined by Eq. 22 .

From Eq. 22 we have that there are two effects of $b$ on $x$. First, an increase in $b$ lowers the risk premium of production $\pi$, thus increasing the marginal benefits from additional production (the LHS of Eq. 22 increases). This causes $x$ to increase. The second effect arises because a higher $b$ reduces the domestic 
benefits of production and, therefore, production falls. This is the incentive effect emphasized in this paper. The next Proposition shows that at the optimal degree of risk sharing, denoted $b^{*}$, the latter effect always dominates.

Proposition $2 x^{\prime}(b)<0$ for $b=b^{*}$.

Proof For an interior solution for $b^{*}$ we have $\widetilde{c}^{\prime}\left(b^{*}\right)=0$ in Eq. 24 and from $-\pi^{\prime}(b)>0$ it follows that $\phi_{f, b}<0$ and hence $x^{\prime}(b)<0$. Non-existence of corner solutions follows from Eq. 24: for $b=0$, the second terms vanishes and we have directly $\widetilde{c}^{\prime}(0)>0$. For $b=1$, the first term vanishes because $\pi^{\prime}(1)=0$. Furthermore, $x^{\prime}(b)<0$ since because of $\pi^{\prime}(1)=0$ there is no impact of $b$ on $x$ through a reduced risk premium. Hence $\widetilde{c}^{\prime}(1)<0$ and it follows with steadiness of $\widetilde{c}^{\prime}\left(b^{*}\right)$ that $0<b^{*}<1$.

As an immediate corollary of Proposition 2 we have that complete risk sharing $(b=1)$ is never optimal. This is because at $b=1$, the effect of a marginal decrease in risk sharing on the risk premium is zero (i.e., $\pi^{\prime}(1)=0$ ), while there are still costs in terms of distorting production.

\section{Corollary 1 Full risk sharing is never optimal.}

We next parameterize the model. As costs arising from moral hazard are inherently difficult to quantify, the purpose is not to obtain an estimate of the optimal degree of diversification. Rather, the aim of the exercise is to study whether there are plausible parameter values that would make a substantial lack of risk sharing optimal. Moreover, and probably related, we are interested in whether the costs of excessive risk sharing (that is risk sharing beyond the optimal degree) could be large. Addressing these questions is crucial for assessing the potential importance of our theory.

To this end we add more structure and assume that the production function is given by $f(x)=x^{\alpha}$ and that there are constant marginal costs $z(x)=\tau x$. From Eq. 24 one can then derive an expression for $b^{*}$ that is defined implicitly by the parameters $\alpha, \gamma, \sigma^{2}, \sigma^{* 2}$ and $\chi$ (the cost parameter $\tau$ drops out). ${ }^{7}$

We set the parameters as follows. $\alpha$ is the parameter that determines the elasticity of output. Since $\phi_{f, b}<0$ at $b^{*}$, a more elastic output (higher $\alpha$ ) increases the marginal cost of additional risk sharing (second term in Eq. 24) and thus lowers $b^{*}$. We choose $\alpha$ to match empirical estimates for the output elasticity of taxation. ${ }^{8}$ For this we assume that taxes are in the form of output taxes. From Eq. 22 we obtain then a tax elasticity $\phi_{f, t}=-\alpha /(1-\alpha)(1-t)$. Vedder and Gallaway (1997) review studies of the marginal cost of public funds

\footnotetext{
${ }^{7}$ This is done by setting Eq. 24 to zero, substituting $x^{\prime}(b)$ (which can be derived by differentiating Eq. 22 with respect to $b)$ and using $\pi^{\prime}(b)=-\gamma(1-b) \sigma^{2}$.

${ }^{8}$ Fixed factors (whose provision cannot be distorted) are thereby implicitly taken account of as they lead to a lower elasticity estimate.
} 
in the US and report a midpoint estimate of $40 \%$. For an US tax-output ratio of around $22 \%$, this translates into $\phi_{f, t} \approx-3$ and $\alpha \approx 0.7 .^{9}$

The parameters $\gamma, \sigma^{2}$ and $\sigma^{* 2}$ are chosen to produce welfare gains from international risk sharing consistent with previous literature. These welfare gains have been computed in the absence of production distortions, i.e., when $\chi=0$. We measure them by the ratio of the certainty equivalent of consumption under full risk sharing and the certainty equivalent of consumption in the absence of risk sharing, computed for the level of $x$ that arises in the absence of risk sharing, $x_{0} .{ }^{10}$ These gains are given by

$$
\text { gain }=\frac{\widetilde{c}_{1}\left(x_{0}\right)}{\widetilde{c}_{0}\left(x_{0}\right)}=\frac{f\left(x_{0}\right)\left(1-\pi_{1}\right)-\tau x_{0}}{f\left(x_{0}\right)\left(1-\pi_{0}\right)-\tau x_{0}}
$$

where the subindexes 0 and 1 refer to no risk sharing and full risk sharing, respectively. Using $\tau=\left(1-\pi_{0}\right) f^{\prime}\left(x_{0}\right)$ (Eq. 22 for $\left.\chi=0\right)$ and $f^{\prime}(x) x=\alpha x^{\alpha}=$ $\alpha f(x)$, Eq. 25 can be simplified to

$$
\text { gain }=\frac{\left(1-\pi_{1}\right) /\left(1-\pi_{0}\right)-\alpha}{1-\alpha}
$$

where $\pi_{0}=\frac{\gamma}{2}\left(\sigma^{2}+\sigma^{* 2}\right)$ and $\pi_{1}=\frac{\gamma}{2} \sigma^{* 2}$.

We set the rate of risk aversion $\gamma$ to 3 (which is the standard parameter used in macroeconomics) and set the variance of output to $\sigma^{* 2}=0.01$. We then choose $\sigma^{2}$ to yield welfare gains of 3\%, i.e., a gain of $1.03 .{ }^{11}$ Such gains are at the upper end of estimates for the unexploited gains from international risk sharing (as surveyed by Wincoop 1999). ${ }^{12}$

We cannot sensibly attach a value to the moral hazard parameter $\chi$, as it is a reduced form parameter. We will therefore present the results as a function of $\chi$. However, as discussed in the previous section, forces that mitigate moral hazard are unlikely to be effective. Hence, although we cannot provide an estimate for $\chi$, we would expect its value to be significantly above zero (which is the value for which there are no moral hazard problems).

Figure 1 depicts the numerical solutions for $b^{*}$ as a function of $\chi$. As to be expected, we have that the optimal degree of risk sharing is 1 when there

\footnotetext{
${ }^{9}$ The marginal cost of public funds is the marginal loss of consumption caused by a marginal increase in tax revenues (under the assumption that tax revenues are returned to households, i.e., $c=f(x)-z(x))$. Given tax revenues $T=t f(x)$ and the household's first order condition $(1-t) f^{\prime}(x)=z^{\prime}(x)$ (ignoring uncertainty here), the marginal cost of public funds is given by $M C P F=-c^{\prime}(T)=-\left(f^{\prime} x^{\prime}(T)-z^{\prime} x^{\prime}(T)\right)=-t f^{\prime} x^{\prime}(T)$. Substituting $x^{\prime}(T)$ in $x^{\prime}(t)=x^{\prime}(T) T^{\prime}(t)=$ $x^{\prime}(T)\left(f+t f^{\prime} x^{\prime}(t)\right)$, solving for $x^{\prime}(t)$ and plugging into $\phi_{f, t}=f^{\prime} x^{\prime}(t) / f$ gives $\phi_{f, t}=-M C P F /(t(1+$ $M C P F)$.

${ }^{10}$ These are the so-called static welfare gains that most of the literature focuses on. They ignore the impact of risk sharing on the level of production. We turn to such dynamic gains later in this section.

${ }^{11}$ It turns out that, numerically, $b^{*}$ depends only on gain but not on its parameterization in terms of $\sigma^{2}, \sigma^{* 2}$ and $\gamma$. Thus, although other combinations of $\sigma^{2}, \sigma^{* 2}$ and $\gamma$ are plausible as well, this would not affect the results.

${ }^{12}$ Unexploited gains refer to the welfare gains from moving from the actual degree of risk sharing to full risk sharing. They thus understate the total gains from risk sharing. However, since the extent of international risk sharing is low, the difference is likely to be negligible.
} 


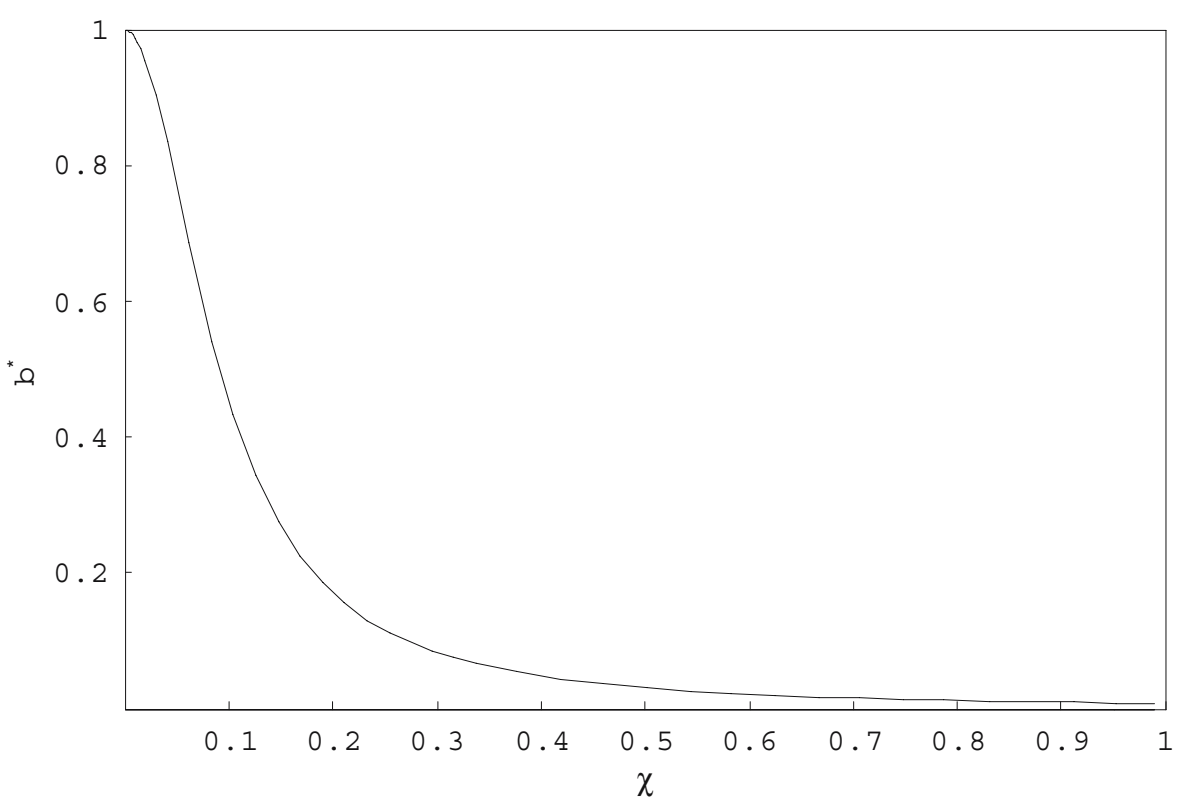

Fig. 1 Optimal degree of international diversification

are no incentive problems (i.e., $b^{*}=1$ for $\chi=0$ ). Furthermore, we also have that $b^{*}$ decreases with $\chi$. The main message from Fig. 1, however, is that the optimal extent of diversification is low for a wide range of $\chi$. For example, for a relatively modest $\chi$ of 0.2 it is about $20 \%$ and for a $\chi$ of 0.4 it is only $5 \%$.

Figures 2 and 3 analyze the sensitivity of the optimal degree of risk sharing with respect to the crucial parameters. Figure 2 depicts $b^{*}$ for different output elasticities $\alpha$ ( $\alpha=0.3,0.5,0.7,0.9$, corresponding to production elasticities $\phi=$ $1 /(1-\alpha)$ between 1.4 and 10) and Fig. 3 for different levels of gains from risk sharing (1,3 and 10\%). As expected, increases in $\alpha$ and decreases in gain result in a higher $b^{*}$. Moreover, the figures show that while $b^{*}$ is relatively robust to changes in welfare gains, it is somewhat more sensitive to changes in the elasticity parameter.

Figure 4 depicts the overall welfare gains (i.e., also taking into account the costs of moral hazard) associated with different degrees of $b(10,25$ and $50 \%)$ as a function of $\chi$. Welfare is thereby measured in units of certainty equivalents of consumption, normalized to yield 1 in the absence of risk sharing. Figure 4 shows that for small $\chi$ modest gains arise. However, larger values of $\chi$ can lead to substantial welfare losses. For example, $50 \%$ diversification leads to a welfare loss of $20 \%$ for a $\chi$ of 0.5 .

Our calibration of the optimal degree of diversification has only taken account of the gains from risk sharing that arise directly from a reduction in consumption variability. It has been pointed out that there are also indirect gains because risk sharing can stimulate investment by reducing risk premia in the economy. Higher investment, in turn, may lead to higher growth. Such 


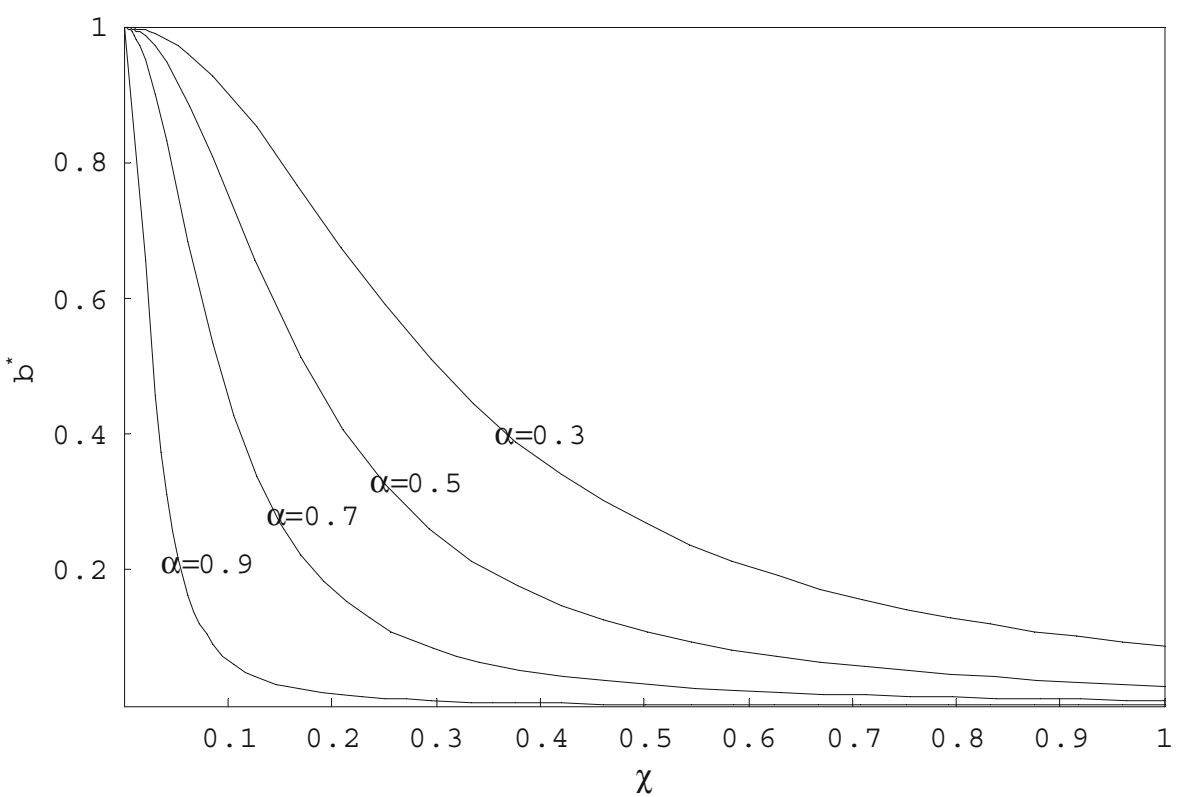

Fig. 2 Optimal degree of international diversification: sensitivity to $\alpha$

indirect gains have been shown to be potentially very important (e.g., Obstfeld 1994, finds indirect gains of up to 100\%). Incorporating such indirect welfare effects from changes in investment into our analysis is expected to reduce the optimal degree of risk sharing $b^{*}$. This is because Proposition 2 shows that at $b^{*}$ the impact of additional risk sharing on investment is negative $\left(x^{\prime}(b)<0\right)$. Hence, starting from $b^{*}$, a reduction in $b$ is welfare improving if there are additional welfare gains from increased investment. $b^{*}$ should, therefore, be interpreted as an upper bound on the optimal degree of diversification. ${ }^{13}$

\subsection{Incentive problems and the low degree of international risk sharing}

What are the implications of these results for the efficiency of the actual degree of international diversification? Sørensen and Yosha (1998) report that only 5\% of shocks to GDP are insured across OECD countries. According to our preferred parameterization (Fig. 1), a $\chi$ of around $40 \%$ is required in order for this to be optimal. An informal interpretation of $\chi=0.4$ is that the representative input is to $40 \%$ chosen according to the government's first order condition and to $60 \%$ efficiently. Hence, no implausibly high value for $\chi$ is needed to make the actual degree of international risk sharing efficient.

\footnotetext{
${ }^{13}$ Devereux and Smith (1994) have identified another channel through which international risk sharing can affect welfare. It arises because international risk sharing reduces precautionary savings, which can lead to lower human capital accumulation. This channel is independent of ours and should, therefore, further lower the optimal degree of diversification.
} 


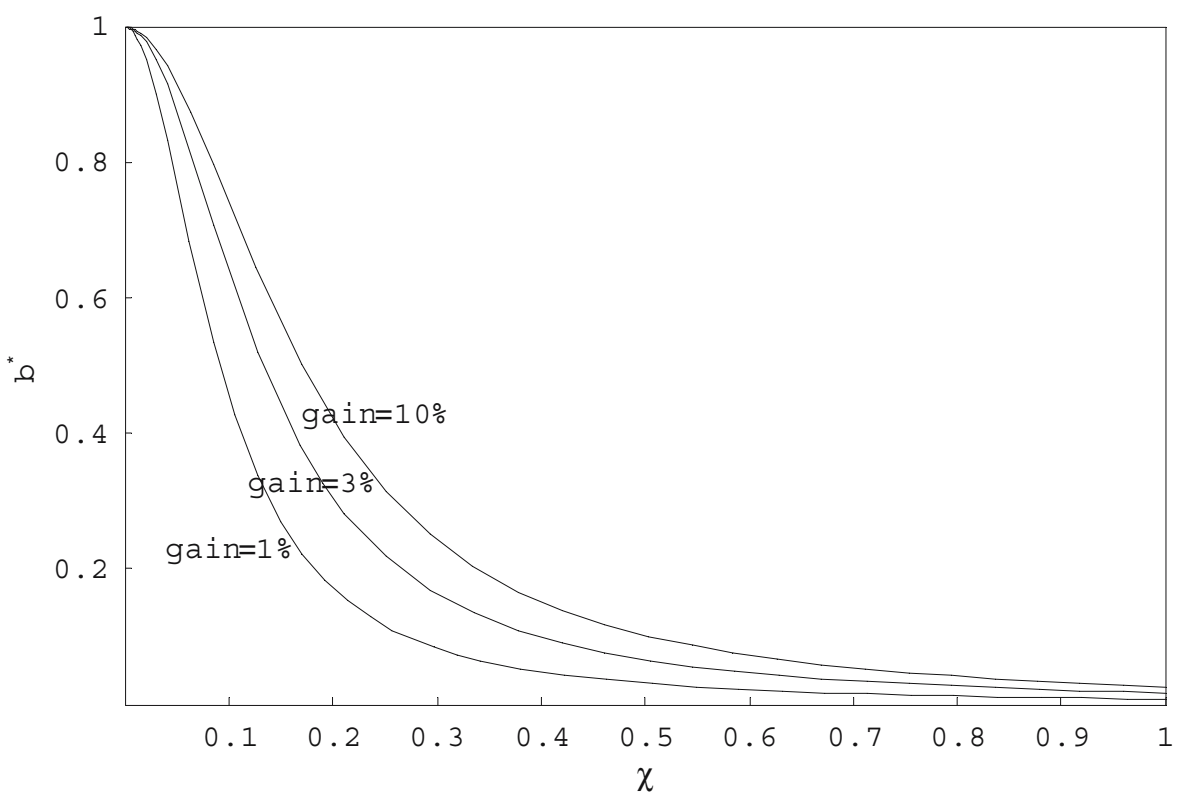

Fig. 3 Optimal degree of international diversification: sensitivity to gain

Given that $b^{*}$ is an upper bound on the optimal degree of international diversification and that the discussion in the previous section suggested that $\chi$ may be rather large, it may even be that the actual degree of risk sharing is excessive. Taken together, our simple parameterization hence suggests that once potential moral hazard costs are taken into account, there is no reason to believe that the currently observed degree of risk sharing is inefficiently low.

A different question though is whether our theory can also explain why there is so little risk sharing across countries. As shown in Proposition 1, insufficient risk sharing incentives on the side of households do not form an explanation. However, the absence of more complete international risk sharing may be the result of government policies that aim at imposing a socially efficient degree of risk sharing. There are indeed several reasons that suggest a significant role for the government in determining risk sharing in the economy.

To start with, governments set the incentives for individual risk sharing. They do this, for example, through their treatment of financial investments at home and abroad for tax purposes. Moreover, while we have focused so far on risk sharing by households, governments also can (and do) carry out risk sharing. In fact, in many respects governments have an advantage in dealing with country-specific risks since they can make tailored contracts with other governments or supranational organizations. Examples of such contracts are the structural funds within the EU or international financial aid orchestrated by the IMF, which are both risk sharing devices. Furthermore, it has been argued that risk sharing institutions are underprovided by the private sector (Allen and Gale 1994; Shiller 1993). Hence, if governments do not provide 


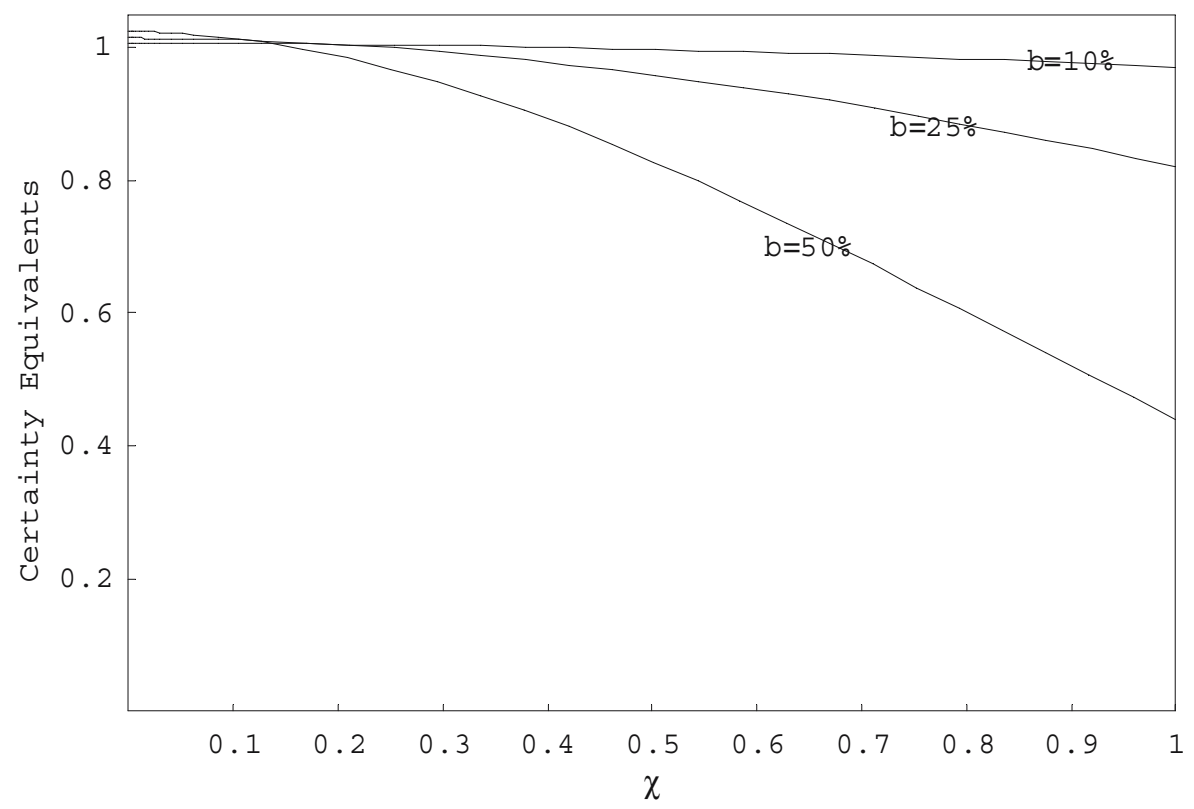

Fig. 4 Welfare effects of international diversification

risk sharing (or implement institutions that allow for effective risk sharing), this may not be compensated for through private risk sharing.

There is also evidence that is consistent with governments being reluctant to facilitate international risk sharing. First, Sørensen and Yosha (1998) find that $92 \%$ of risk sharing within the OECD takes place on the individual level, although various channels for government risk sharing are operative. This is surprising given the fact that (as just discussed) governments should have an advantage over households in providing risk sharing but could be explained by their incentives to limit international risk sharing. Second, there exist government-imposed frictions to international risk sharing that could be justified as a mean of discouraging individual risk sharing. For example, the current international tax system makes investment abroad disadvantageous. ${ }^{14}$

Third, there is also differential evidence consistent with this argument. If the welfare costs of production distortions are important and governments can indeed influence the extent of risk sharing in the economy, then we would expect risk sharing to be greater across countries or jurisdictions where distortions in government policies are less of an issue. This is likely to be the case across US states because federal policies should not be distorted by intra-state risk sharing (only state policies may be distorted). Moreover, the common legal system may make it easier to deal with distortions at the

\footnotetext{
${ }^{14}$ This is, first, because tax credits on foreign withholding taxes are usually imperfect (in particular for capital gains). Second, governments effectively subsidize investment at home through dividend imputation schemes.
} 
state level (for example, by acting as a commitment device). In support of this prediction, Sørensen and Yosha find that $60 \%$ of all shocks to income are insured among US states, compared to only 5\% among the OECD countries. Furthermore, given that the problem of production distortions may be more pronounced among OECD countries, we would expect OECD countries to make relatively greater use of means of reducing consumption risk that do not create production distortions. For example, intertemporal consumption smoothing (through international borrowing and lending) reduces consumption risk but does not distort production incentives since it does not require insuring domestic income. Consistent with this, Sørensen and Yosha find that within the OECD $80 \%$ of reductions in consumption variability are due to intertemporal consumption smoothing, compared to only $11 \%$ within the US.

\section{Conclusions}

This paper has analyzed distortions in government policies due to international risk sharing. We have shown that the welfare costs from such distortions may be very large. In particular, they can make a low degree of risk sharing across countries actually desirable. As we have argued, the lack risk sharing across countries may therefore be the result of government actions aiming at avoiding excessive risk sharing.

Our analysis has further revealed a conflict between households' incentives for risk sharing and socially optimal risk sharing. Continuing financial innovation and integration may thus reduce welfare by limiting the government's ability to influence risk sharing in the economy, while, at the same time, stimulating households' risk sharing.

It should be emphasized that there are several mechanisms that could potentially mitigate government moral hazard, such as the possibility for the government to commit to future policies, reputational effects or the international mobility of capital. Whether they are effective in constraining distortions depends largely on what means of risk sharing are available. If households have effective risk sharing instruments at their disposal, they can insure their country in a variety of dimensions, which would limit the role of these mechanisms.

Acknowledgements The author would like to thank Lans Bovenberg, Giancarlo Corsetti, Jacques Drèze, Patrick François, Vitor Gaspar, Assaf Razin, Robert Shiller, the late Oved Yosha and participants of presentations at several workshops and seminars for helpful comments. The paper has also benefitted substantially from the suggestions of an anonymous referee and the Editor.

\section{References}

Allen F, Gale D (1994) Financial innovation and risk sharing. MIT Press, Cambridge, MA

Atkeson A (1991) International lending with moral hazard and risk of repudiation. Econometrica 59(4):1069-1089 
Calcagno R, Wagner W (2006) Dispersed initial ownership and the inefficiency of the stock market under moral hazard. J Math Econ 42:36-45

Calvo GA (2000) Betting against the state: socially costly financial engineering. J Int Econ 51:5-19

Courchene TJ, Purvis DD (1993) Productivity, growth, and Canada's international competitiveness. The John Deutsch Institute for the Study of Economic Policy, Queen's University

Devereux MB, Smith GW (1994) International risk sharing and economic growth. Int Econ Rev 35(3):535-550

Drèze $\mathrm{J}$ (2000) Economic and social security in the twenty-first century, with attention to Europe. Scand J Econ 102:342-353

Eaton J, Gersovitz M (1981) Debt with potential repudiation: theoretical and empirical analysis. Rev Econ Stud 48:289-309

Eijffinger S, Wagner W (2001) Taxation if capital is not perfectly mobile: tax competition versus tax exportation. CEPR discussion paper no 3084

Fischer S (1998) Capital account liberalization and the role of the IMF. In: Fischer S (ed) Should the IMF pursue capital account convertibility? Princeton University Press, Princeton, NJ, pp 1-10

French KR, Poterba JM (1991) Investor diversification and international equity markets. Am Econ Rev 81(2):222-226

Gertler M, Rogoff K (1990) North-south lending and endogenous capital-market inefficiencies. J Monet Econ 26:245-66

Huizinga H, Nicodème G (2006) Foreign ownership and corporate income taxation: an empirical evaluation. Eur Econ Rev 50(5):1223-1244

Huizinga H, Nielsen SB (1997) Capital income and profit taxation with foreign ownership of firms. J Int Econ 42:149-165

Kocherlakota NR (1998) The effects of moral hazard on asset prices when financial markets are complete. J Monet Econ 41:39-56

Kremer M, Mehta P (2000) Globalization and international public finance. NBER working paper no 7575

Lewis KK (1999) Trying to explain the home bias in equities and consumption. J Econ Lit 37: $571-608$

Magill M, Quinzii M (1998) Theory of incomplete markets. MIT Press, Cambridge, MA

Magill M, Quinzii M (2002) Capital market equilibrium with moral hazard. J Math Econ 38: 149-190

Obstfeld M (1994) Risk-taking, global diversification, and growth. Am Econ Rev 84(5):1310-1329

Pollock SH (1991) Mechanisms for exporting the state sales tax burden in the absence of federal deductibility. Natl Tax J 44:297-310

Pratt J (1964) Risk aversion in the small and the large. Econometrica 32:217-229

Sachs J (1989) The debt overhang of developing countries. In: Guillermo PK, Calvo A, Ronald Findlay, de Macedo JB (eds) Debt stabilization and development: essays in memory of Carlos Diaz-Alejandro. Blackwell, Oxford

Shiller RJ (1993) Macro markets: creating institutions to manage society's largest economic risks. Clarendon, Oxford

Sørensen BE, Yosha O (1998) International risk sharing and European monetary unification. J Int Econ 45:211-238

The Economist (2002) October 19th, p 85

Tirole J (2002) Financial crises, liquidity, and the international monetary system. Princeton University Press, Princeton, NJ

Tirole J (2003) Inefficient foreign borrowing: a dual- and common-agency perspective. Am Econ Rev 93:1678-1702

Vedder R, Gallaway L (1997) Out of work: unemployment and government in twentieth-century America. New York University Press, New York

Wincoop EV (1999) How big are the potential welfare gains from international risksharing?. J Int Econ 47:109-135 